\title{
The application of the percutaneous suturing technique in thoracoscopic repair of congenital diaphragmatic hernia
}

\author{
Bartosz Bogusz ${ }^{1, A-D, F}$, Adam Mol ${ }^{1, B, C, E}$, Oskar Zgraj ${ }^{2, A, D, E}$, Wojciech Górecki ${ }^{3, B, E, F}$ \\ ${ }^{1}$ Department of Pediatric Surgery, University Children's Hospital, Jagiellonian University Medical College, Kraków, Poland \\ 2 Department of Pediatric Surgery, St. Luke Regional Hospital, Tarnów, Poland \\ ${ }^{3}$ Depertment of Pediatric Surgery, University Children's Hospital, Jagiellonian University Medical College, Kraków, Poland \\ A - research concept and design; $\mathrm{B}$ - collection and/or assembly of data; $\mathrm{C}$ - data analysis and interpretation; \\ $\mathrm{D}$ - writing the article; $\mathrm{E}$ - critical revision of the article; $\mathrm{F}$ - final approval of the article
}

Address for correspondence

Bartosz Bogusz

E-mail: bjbart@poczta.onet.pl

Funding sources

None declared

Conflict of interest

None declared

Received on February 12, 2020

Reviewed on March 15, 2020

Accepted on May 14, 2020

Published online on September 1, 2020

\begin{abstract}
Background. Thoracoscopic surgery of congenital diaphragmatic hernia (CDH) is connected with a higher incidence of recurrence than open repair is. This is usually caused by the dehiscence of sutures in the lateral part of the defect. This area is characterized by increased tension on proximate tissues and difficult thoracoscopic suturing. For more effective repair, the authors adopted a variant of percutaneous internal ring suturing (PIRS) technique.
\end{abstract}

Objectives. To present and evaluate the efficacy of the PIRS technique for the repair of CDH.

Material and methods. The study is based on retrospective analysis of the medical data of patients with CDH treated in the Department of Pediatric Surgery of the Jagiellonian University Medical College (Kraków, Poland) from January 2013 to July 2019. The PIRS technique was applied when thoracoscopic repair under acceptable tension appeared impossible.

Results. Fifty-one patients were identified. Of these, 11 children died before surgery and 1 after, leaving $39(76 \%)$ who were operated on and survived. Thoracoscopy was used in 27 cases (69\%), with 3 conversions. The recurrence rate in patients who underwent thoracoscopic closure of the defect with intermittent sutures was $27 \%$ (3 out of 11 children), while in the group that underwent thoracoscopic repair with the additional use of percutaneous suturing, the recurrence rate was $6.25 \%$ (1 out of 16 patients). The follow-up periods ranged from 4 months to 6 years.

Conclusions. The applied PIRS technique permits safe and effective closure of intermediate-size diaphragmatic defects under acceptable tension. The method is feasible and can be listed among countermeasures against recurrence.

Key words: hernia, congenital, thoracoscopy, diaphragmatic, suturing

Cite as

Bogusz B, Mol A, Zgraj 0, Górecki W. The application of the percutaneous suturing technique in thoracoscopic repair of congenital diaphragmatic hernia. Adv Clin Exp Med. 2020;29(8):967-970. doi:10.17219/acem/122396

DOI

10.17219/acem/122396

Copyright

Copyright by Author(s)

This is an article distributed under the terms of the

Creative Commons Attribution 3.0 Unported (CC BY 3.0)

(https://creativecommons.org/licenses/by/3.0/) 


\section{Introduction}

The classical surgical approach to the repair of a congenital diaphragmatic hernia $(\mathrm{CDH})$ is transverse subcostal laparotomy. The first case of successful laparoscopic repair of this pathology was reported in $1995,{ }^{1}$ while the thoracoscopic approach was first described in $2001 .^{2}$ Nowadays, thoracoscopic access presents a popular strategy of surgical treatment in children with CDH. However, numerous authors report a higher incidence of recurrence in patients with CDHs following thoracoscopic repair, as compared to open surgery. ${ }^{3,4}$ Most of those complications result from the dehiscence of sutures within the most lateral part of the defect.

The pathology of $\mathrm{CDH}$ presents a wide spectrum of defects ranging from small, oval or cigar-shaped lesions to those involving over $90 \%$ of the hemi-diaphragm. In 2014, the Congenital Diaphragmatic Hernia Study Group (CDHSG) developed a staging system to describe the variability of diaphragmatic defects. ${ }^{5}$ This system has been shown to correlate strongly with mortality in patients with $\mathrm{CDH} .{ }^{6}$ Depending on their size, diaphragmatic defects in $\mathrm{CDH}$ were divided into 4 groups (A-D). From the surgical perspective, the defects classified as groups $\mathrm{C}$ and D qualify for mesh repair. Small group A defects require a primary repair with interrupted sutures.

Patients classified as group B present with an intermediate-size defect. Intraoperatively, following the reduction of the viscera into the abdomen, these do not usually warrant a mesh repair. However, poor development of the posterior rim of the diaphragm and the resulting increased stretch of the approximated edges of the defect produce an increased risk of recurrence. Moreover, thoracoscopic suturing is usually less feasible in the costodiaphragmatic recess, which presents another important risk of suture line dehiscence. To cope with this problem, the authors decided to adopt a variant of the percutaneous internal ring suturing (PIRS) technique described by Patkowski et al.

The aim of this study was to present the efficacy and feasibility of the PIRS technique in the treatment of $\mathrm{CDH}$ in children, with particular emphasis on avoiding hernia recurrence.

\section{Material and methods}

A retrospective analysis was performed, reviewing the medical data of 51 patients with $\mathrm{CDH}$ treated between January 2013 and July 2019 in the Department of Pediatric Surgery at the University Children's Hospital of Jagiellonian University Medical College in Kraków (Poland).

The percutaneous method of suturing has been used in this department since January 2016, in cases when, in the surgeon's opinion, the completion of the thoracoscopic repair of the diaphragmatic defect with simple interrupted sutures was possible, but resulted in excessive tension in the part adjacent to the chest wall. In these patients, the diaphragmatic defects were recognized as group $\mathrm{B}$ according to the CDHSG classification criteria.

\section{Surgical technique}

Thoracoscopies were performed in the lateral decubitus position. Single-lung ventilation was not utilized. We prefer to use 3-5 $\mathrm{mm}$ ports. After the reduction of the herniated viscera, the size of the defect was evaluated and the course of action was determined. Defects qualifying as CDHSG groups $C$ and $D$ were repaired with mesh, employing thoracoscopic access or laparotomy. Small group A-type defects were repaired with interrupted 2.0 non-absorbable braided sutures after delineation and scarification of the edges. Intermediate-size group B defects were characterized by poor development or the complete absence of a significant portion of the postero-lateral diaphragmatic rim. Even after careful mobilization of this structure, there was excessive tension on the antero-medial margin of the diaphragm. This resulted in an increased risk of tearing the diaphragmatic muscle during its approximation to the hypoplastic postero-lateral edge and the chest wall. For these patients, the authors decided to adopt the PIRS technique developed by D. Patkowski for single port laparoscopic repair of an inguinal hernia. ${ }^{7}$ The first step was the scarification of the pleura covering the selected rib and the free margin of the diaphragmatic flap. The medial part of the defect was repaired with interrupted non-absorbable braided 2.0 sutures. In the lateral part of the defect, where the posterolateral edge of the diaphragm was hypoplastic or absent, a percutaneous suturing technique similar to the PIRS method was applied, in order to facilitate fixation and reduce tension on the suture line. The percutaneous suturing technique is presented in Fig. 1. We used non-absorbable braided 2-0 sutures, introduced through an 18G injection needle. The tip of the needle was slightly curved to facilitate its manipulation within tissues. The puncture sites on the skin were closed with strips, leaving almost no scar. A single skin incision was used to create up to 3 percutaneous sutures. One of the 2 puncture sites of each suture was above the selected rib, while the other was below it.

\section{Results}

The retrospective analysis identified the medical records of 51 patients with CDH treated at our center. Of these, 11 died before surgical intervention and 1 died after surgery because of a generalized Gram-negative infection. Thirtynine $(76 \%)$ were operated on and survived. Thoracoscopy was applied in 27 of them (69\%). In 3 children (13\%), conversion to laparotomy was necessary because of the size of the defect and the need for mesh repair.

The recurrence rate in the group of patients operated on by thoracoscopic access was 15\% (4 patients). There were 

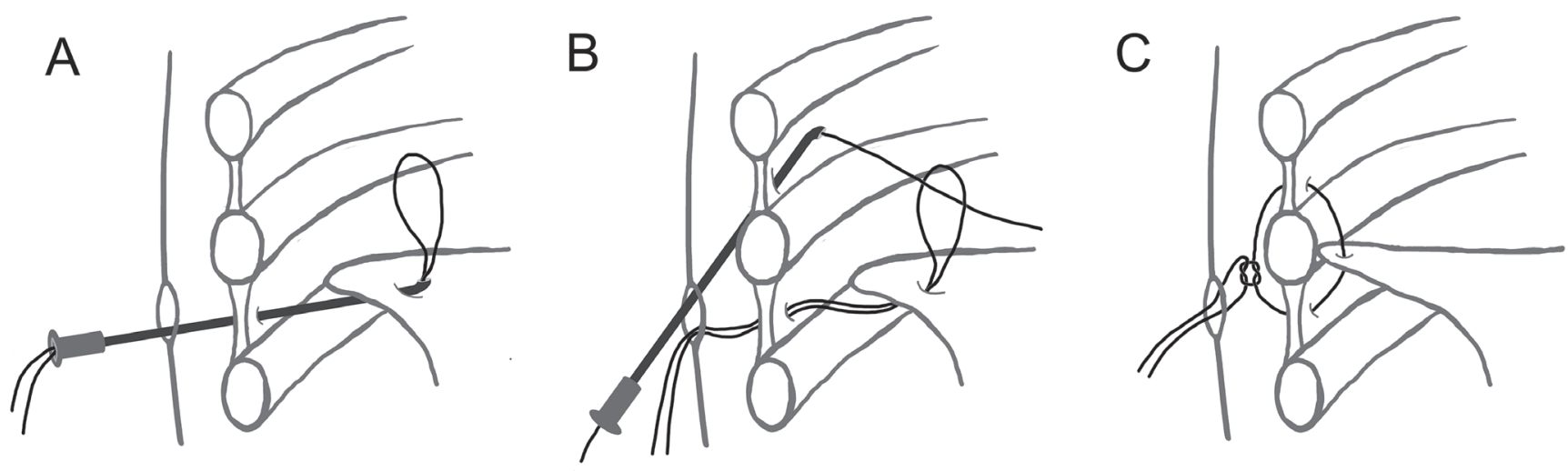

Fig. 1. Technique of percutaneous suturing in $\mathrm{CDH}$, adopted from the PIRS method

no recurrences in the patients who underwent open repair. In all patients, the cause of recurrence was disruption of the suture line within the costodiaphragmatic recess.

In the group of patients who underwent thoracoscopic repair with the use of simple intermittent sutures (11 patients), the recurrence rate was very high, reaching $27 \%$ (3 children). All of these recurrences occurred in children operated on between January 2013 and December 2015, and were managed using transverse subcostal laparotomy. None of the patients with recurrent $\mathrm{CDH}$ required mesh repair during the re-do.

Among the 16 patients who underwent thoracoscopic closure with the use of percutaneous sutures, there was only 1 case of hernia recurrence (6.25\%), diagnosed in 2017.

The group of patients subjected to thoracoscopic repair with the application of percutaneous sutures included 13 newborns operated on between the $2^{\text {nd }}$ and $5^{\text {th }}$ day of life, and 3 children with late presentations of the pathology at the ages of 8 and 15 months. Intraoperatively, these defects were all categorized as group B defects according to the CDHSG classification. The only recurrence in this group consisted in herniation of the greater momentum between the sutures anchoring the diaphragmatic muscle to the chest wall. This complication was diagnosed during routine ultrasound examination on the $5^{\text {th }}$ day after surgery. The problem was repaired immediately through thoracoscopic access (Fig. 2). The intervention consisted in the addition of percutaneous stitches introduced thorough the points on the skin used during the first operation. The patient's further clinical course was uneventful. No other complications related to the operative technique were observed. The follow-up period varied from 4 months to 6 years.

\section{Discussion}

Since the first reports, published in $2001,{ }^{2}$ thoracoscopic repair has become a very popular strategy for surgical treatment in children with $\mathrm{CDH}$. Minimally invasive techniques offer numerous advantages, such as improved

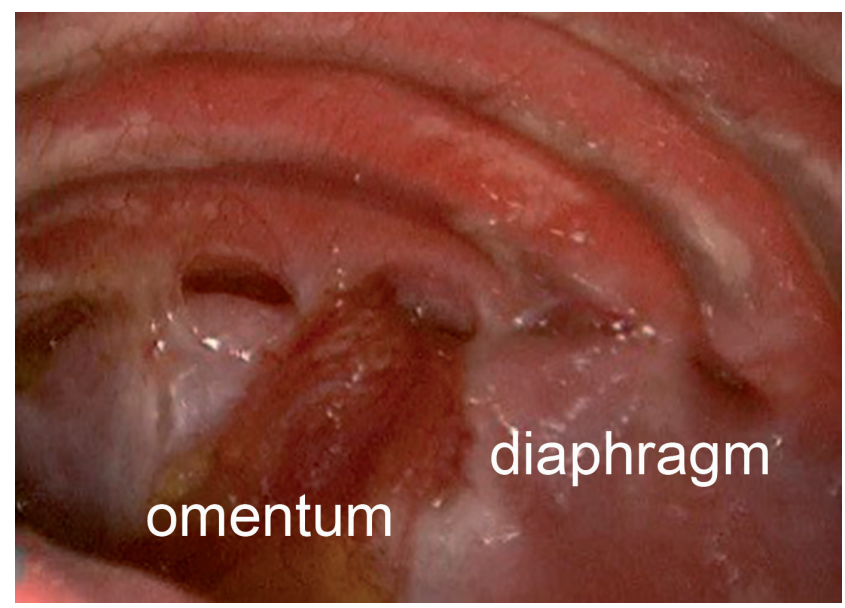

Fig. 2. $\mathrm{CDH}$ recurrence after thoracoscopic repair

visualization, reduction of postoperative opioid intake, shorter length of intubation, and improved cosmesis. ${ }^{8} \mathrm{Nev}-$ ertheless, the main goal of $\mathrm{CDH}$ treatment is a durable repair.

Studies consistently report a higher recurrence rate in patients who have undergone thoracoscopic $\mathrm{CDH}$ interventions. ${ }^{3,8-11}$ Initial five-year experience of our institution with thoracoscopic treatment of $\mathrm{CDH}$ also showed a high percentage of recurrent herniation. According to the available clinical data, the higher risk of recurrence in children who have undergone thoracoscopic procedures cannot be explained by demographic data, the severity of illness or nonsurgical therapeutic procedures before and/or after surgery. ${ }^{4,11}$

Gander et al. presented a list of technical difficulties that can be responsible for a high relapse percentage in children who have undergone a thoracoscopic $\mathrm{CDH}$ correction. ${ }^{4}$ In cases of intermediate and large defects, the posterolateral part of the diaphragm is usually atrophic or hypoplastic and vulnerable, especially after its mobilization by partial dissection from the chest wall. Thoracoscopic suturing at this site is not feasible, which, in combination with the tension on proximate structures, can increase the risk of disruption. 
In our patients, all cases of recurrent herniation were caused by a relatively small dehiscence of diaphragmatic sutures in the most lateral part of the defect. Therefore, we decided to focus on effective and feasible methods that allow anchoring the well-developed antero-medial margin of the defect directly to the adjacent rib. Several literature reports have been published about various methods of percutaneous suturing that allow these structures to be fixed in a safe and effective way. ${ }^{12,13}$ Because of our previous experience with the PIRS method, we decided to adopt it in this procedure in order to achieve solid fixation of the lateral section of the diaphragmatic defect to the chest wall. We observed only 1 recurrence in 16 patients (all with group B defects according to CDHSG) who had undergone thoracoscopic repair with the use of percutaneous suturing. The different outcomes observed over the whole period of this study between the groups of patients treated thoracoscopically with and without the application of the percutaneous suturing technique could be explained by both the effect of the learning curve, and by the feasibility and efficacy of percutaneous diaphragm fixation. Starting from 2015, we also adopted a lower threshold for utilization of mesh repair in larger diaphragmatic defects (CDHSG groups C and D). We believe that these 2 factors combined allowed the reduction of the overall number of recurrences in patients with CDHs within the period from January 2015 to July 2019 (8\%, 2 patients).

In the light of the relatively high recurrence rate after thoracoscopic repair of $\mathrm{CDH}$, the controversies concerning the optimal treatment method remain unsolved. ${ }^{4,14,15}$ Nevertheless, in our opinion, the benefits of thoracoscopic intervention outweigh the potential risk of recurrence, which can easily be detected and managed with the same method.

\section{Conclusions}

The technique of percutaneous suturing allows for the safe and effective closure of the posterolateral part of diaphragmatic defects in $\mathrm{CDH}$. It permits a feasible repair under acceptable tension, and can be listed among countermeasures against recurrence. The technique should be considered in CDHSG group A and B cases where simple interrupted suturing does not ensure an uneventful recovery because of the size or morphology of the defect.

\section{ORCID iDs}

Bartosz Bogusz (D) https://orcid.org/0000-0002-8763-0990 Adam Mol (i) https://orcid.org/0000-0001-9378-549X

Oskar Zgraj (D) https://orcid.org/0000-0003-1738-2482

Wojciech Górecki (D) https://orcid.org/0000-0003-4907-0520

\section{References}

1. Zee DCVD, Bax NMA. Laparoscopic repair of congenital diaphragmatic hernia in a 6-month-old child. Surg Endosc. 1995;9(9):1001-1003. doi:10.1007/bf00188460

2. Becmeur F, Jamali R, Moog R, et al. Thoracoscopic treatment for delayed presentation of congenital diaphragmatic hernia in the infant. Surg Endosc. 2001;15(10):1163-1166. doi:10.1007/s004640090064

3. Lansdale N, Alam S, Losty PD, Jesudason EC. Neonatal endosurgical congenital diaphragmatic hernia repair. Ann Surg. 2010;252(1):20-26. doi:10.1097/sla.0b013e3181dca0e8

4. Gander JW, Fisher JC, Gross ER, et al. Early recurrence of congenital diaphragmatic hernia is higher after thoracoscopic than open repair: A single institutional study. J Pediatr Surg. 2011;46(7):1303-1308. doi:10.1016/j.jpedsurg.2010.11.048

5. Harting MT, Lally KP. The Congenital Diaphragmatic Hernia Study Group registry update. Semin Fetal Neonatal Med. 2014;19(6):370-375. doi:10.1016/j.siny.2014.09.004

6. Putnam LR, Harting MT, Tsao K, et al. Congenital diaphragmatic hernia defect size and infant morbidity at discharge. Pediatrics. 2016; 138(5):e20162043. doi:10.1542/peds.2016-2043

7. Patkowski D, Czernik J, Chrzan R, Jaworski W, Apoznański W. Percutaneous internal ring suturing: A simple minimally invasive technique for inguinal hernia repair in children. J Laparoendosc Adv Surg Tech A. 2006;16(5):513-517. doi:10.1089/lap.2006.16.513

8. Kim AC, Bryner BS, Akay B, Geiger JD, HirschI RB, Mychaliska GB. Thoracoscopic repair of congenital diaphragmatic hernia in neonates: Lessons learned. J Laparoendosc Adv Surg Tech A. 2009;19(4):575-580. doi:10.1089/lap.2009.0129

9. McHoney M, Giacomello L, Nah SA, et al. Thoracoscopic repair of congenital diaphragmatic hernia: Intraoperative ventilation and recurrence. J Pediatr Surg. 2010;45(2):355-359. doi:10.1016/j.jpedsurg. 2009.10.072

10. Gourlay DM, Cassidy LD, Sato TT, Lal DR, Arca MJ. Beyond feasibility: A comparison of newborns undergoing thoracoscopic and open repair of congenital diaphragmatic hernias. J Pediatr Surg. 2009;44(9): 1702-1707. doi:10.1016/j.jpedsurg.2008.11.030

11. Lao OB, Crouthamel MR, Goldin AB, Sawin RS, Waldhausen JH, Kim SS. Thoracoscopic repair of congenital diaphragmatic hernia in infancy. J Laparoendosc Adv Surg Tech A. 2010;20(3):271-276. doi:10.1089/lap. 2009.0150

12. Chen B, Wang $Q$, Li B, Wang B. Thoracoscopic repair of diaphragmatic hernia in infants: A new modification of the technique. Eur J Pediatr Surg. 2015;26(06):519-523. doi:10.1055/s-0035-1568996

13. Boo Y, Rohleder S, Muensterer O. A novel technique of posterolateral suturing in thoracoscopic diaphragmatic hernia repair. Eur J Pediatr Surg Rep. 2017;05(1):e26-e28. doi:10.1055/s-0037-1604049

14. Inoue M, Uchida K, Otake K, et al. Thoracoscopic repair of congenital diaphragmatic hernia with countermeasures against reported complications for safe outcomes comparable to laparotomy. Surg Endosc. 2015;30(3):1014-1019. doi:10.1007/s00464-015-4287-6

15. Jancelewicz T, Langer JC, Chiang M, Bonnard A, Zamakhshary M, Chiu PP. Thoracoscopic repair of neonatal congenital diaphragmatic hernia (CDH): Outcomes after a systematic quality improvement process. J Pediatr Surg. 2013;48(2):321-325. doi:10.1016/j.jpedsurg. 2012.11.012 